\title{
RESULTS OF THE COMBINED APPLICATION OF VARIOUS SCHEMES OF STIMULATION OF CAVIAR OVULATION IN STERLET PRODUCERS UNDER CONDITIONS OF REGULATED SYSTEMS
}

\author{
Arthur N. Tumenov \\ Scientific and Production Center of Fisheries, Uralsk, Republic of Kazakhstan
}

Ahmediyar M. Dzhunusov

Educational and Scientific Complex of Pilot Industrial Production of Aquaculture, Uralsk, Republic of Kazakhstan

Serik S. Bakiyev

Al-Farabi Kazakh National University, Almaty, Republic of Kazakhstan

\begin{abstract}
The article presents the results of studies of schemes for stimulating ovulation of sturgeon caviar during rearing under conditions of regulated systems. Sturgeon (Acipenseridae) fish are characterized by high quality caviar and meat, and therefore are one of the main objects of cultivation in modern aquaculture. The achievement of sexual maturity of sturgeon fish when grown in facilities with a closed water supply cycle depends on the compliance with temperature and oxygen conditions, as well as species and the general physiological state of the fish itself. In modern aquaculture of sturgeon fish, the main species of cultivation are the following: beluga (Huso huso), Russian sturgeon (Acipenser gueldenstaedtii), Siberian sturgeon (Acipenser baerii), sterlet (Acipenser ruthenus) and their hybrids. Sterlet (Acipenser ruthenus) in comparison with other species of sturgeon fish reaches puberty at a much earlier date. The studies were carried out on the basis of LLP "Educational and Scientific Complex of Pilot Industrial Production of Aquaculture". As it is known, pituitary injections and synthetic drugs activating the pituitary gland of sturgeons are used to stimulate producers. The study used sexually mature sterlet (Acipenser ruthenus) injected according to the combined stimulation schemes for carp pituitary gland and synthetic preparations "Surfagon", "Nerestin-5". To determine the effectiveness of using combined stimulation schemes for carp pituitary gland and synthetic preparations "Surfagon", "Nerestin-5", sterlet producers (Acipenser ruthenus) were divided into 3 groups of 20 individuals. As a result of the studies, the following fish-breeding and biological indicators of sterlet producers (Acipenser ruthenus) have been 응 determined: weight of fish, weight of eggs obtained, as well as percentage of eggs to the total weight of fish.

Key words: sturgeons, gonadotropic hormones, synthetic drugs, reproductive products, caviar.

Citation. Tumenov A.N., Dzhunusov A.M., Bakiyev S.S. Results of the Combined Application of Various Schemes of Stimulation of Caviar Ovulation in Sterlet Producers Under Conditions of Regulated Systems. Natural Systems and Resources, 2020, vol. 10, no. 2, pp. 51-55. (in Russian). DOI: https://doi.org/10.15688/nsr.jvolsu.2020.2.6 УДК 639.3

ББК 47.294

\section{РЕЗУЛЬТАТЫ КОМБИНИРОВАННОГО ПРИМЕНЕНИЯ РАЗЛИЧНЫХ СХЕМ СТИМУЛИРОВАНИЯ ОВУЛЯЦИИ ИКРЫ У ПРОИЗВОДИТЕЛЕЙ СТЕРЛЯДИ В УСЛОВИЯХ РЕГУЛИРУЕМЫХ СИСТЕМ}

\author{
Артур Насибуллаулы Туменов \\ Научно-производственный центр рыбного хозяйства, г. Уральск, Республика Казахстан
}




\section{НОВЫЕ БИОТЕХНОЛОГИИ В АГРОПРОМЫШЛЕННОМ КОМПЛЕКСЕ}

\section{Ахмедияр Мирасович Джунусов}

Учебно-научный комплекс опытно-промышленного производства аквакультуры, г. Уральск, Республика Казахстан

\section{Серик Самигуллович Бакиев}

Казахский национальный университет им. аль-Фараби, г. Алматы, Республика Казахстан

Аннотация. В статье представлены результаты исследований схем стимулирования овуляции икры осетровых рыб при выращивании в условиях регулируемых систем. Осетровые (Acipenseridae) рыбы характеризуются высоким качеством икры и мяса, в связи с чем являются одним из основных объектов выращивания в условиях современной аквакультуры. Достижение половой зрелости осетровых рыб при выращивании в установках с замкнутым циклом водообеспечения зависит от соблюдения температурного и кислородного режима, а также видовой принадлежности и общего физиологического состояния самой рыбы. В условиях современной аквакультуры осетровых рыб основными объектами выращивания являются следующие виды: белуга (Huso huso), русский осетр (Acipenser gueldenstaedtii), сибирский осетр (Acipenser baerii), стерлядь (Acipenser ruthenus) и их гибриды. Стерлядь (Acipenser ruthenus) по сравнению с другими видами осетровых рыб достигает половой зрелости в значительно ранние сроки. Исследования проводились на базе ТОО «Учебно-научного комплекса опытно-промышленного производства аквакультуры». Как известно для стимуляции производителей применяются гипофизарные инъекции и синтетические препараты, активизирующие собственный гипофиз осетровых рыб. В исследовании использовали половозрелых особей стерляди (Acipenser ruthenus) инъецировавших согласно комбинированным схемам стимуляции гипофизом карпа и синтетическими препаратами «Сурфагон», «Нерестин-5». Для определения эффективности применения комбинированных схем стимуляции гипофизом карпа и синтетическими препаратами «Сурфагон», «Нерестин-5» производителей стерляди (Acipenser ruthenus) разделили на 3 группы по 20 особей. В результате исследований определены рыбоводно-биологические показатели производителей стерляди (Acipenser ruthenus), такие как: масса рыбы, масса полученной икры, а также процентное отношение икры к общей массе рыбы.

Ключевые слова: осетровые рыбы, гонадотропные гормоны, синтетические препараты, половые продукты, икра.

Цитирование. Туменов А. Н., Джунусов А.М., Бакиев С. С. Результаты комбинированного применения различных схем стимулирования овуляции икры у производителей стерляди в условиях регулируемых систем // Природные системы и ресурсы. - 2020. - Т. 10, № 2. - С. 51-55. - DOI: https://doi.org/10.15688/ nsr.jvolsu.2020.2.6

Введение. В технологии выращивания осетровых рыб в условиях регулируемых системах одним из важных составляющих элементов являются получение зрелых производителей, у которых икра и сперма пригодны для оплодотворения [7; 8].

Существует несколько методов стимуляции овуляции производителей. Традиционно в индустриальных условиях применялся метод гипофизарных инъекций. Который основан на введении производителям весенне- и летне-нерестующих видов рыб (осетр, карп, лещ, судак, белый амур и др.) препарата гипофиза. Он позволяет ускорить протекание завершающих стадий полового созревания рыб либо преодолеть тормозящее действие условий их содержания на развитие половых продуктов. До разработки препаратов заменителей гонадотропных гормонов на рыбоводных хозяйствах для приготовления необходимых инъек- ций использовали гипофизы, которые заготавливались осенью (карповые), зимой (лососевые и осетровые) и ранней весной (теплолюбивые, растительноядные) во время промысла рыб [5; 6; 9].

В настоящее время в связи со сравнительно высокими ценами на гипофиз производителей осетровых и карпа, возникла необходимость замены их другими гормональными препаратами. Ученые разработали препараты на основе использования рилизинг - гормонов, которые активизируют собственный гипофиз производителей рыб. К таким препаратам относятся «Суфрагон» (ЛГ-РГ-А), «Оваприм», «Оватид», «Овапель», «GnRH» и «Нерестин» [2; 3; 4].

Выращивание осетровых рыб в регулируемых условиях имеет свою специфику проведение искусственной зимовки, особые требования к кормам и гидрохимическому 
режиму, что требует дополнительного изучения применяемых методов для подбора оптимальных, экономически целесообразных схем стимулирования овуляции осетровых рыб.

Целью работы является анализ результатов применения гормональных препаратов и комбинированного применения различных схем стимулирования овуляции у самок стерляди, выращиваемых круглогодично в условиях регулируемых систем.

Материалы и методы исследования. Научно-исследовательские работы были проведены в рамках НИР проекта: «Формирование ремонтно-маточных стад осетровых рыб с применением генетических методов с целью повышения эффективности искусственного воспроизводства». Исследования выполнялись на базе ТОО «Учебно-научного комплекса опытно-промышленного производства аквакультуры» в установках замкнутого водоснабжения (УЗВ). Исследования и эксперимент проводили после проведения «искусственной зимовки» при температуре воды $14{ }^{\circ} \mathrm{C}$ с использованием производителей стерляди (Acipenser ruthenus), вес которых варьировался от 2,6 до 4,3 кг. Производителей стерляди разделили на 3 группы. Первую группу инъецировали препаратом «Нерестин-5» градуально в соотношении 20:80. Проводили предварительную и разрешающую инъекцию самкам, с интервалом в 12 часов. Общая доза препарата составила 0,4 мл/кг веса самки. Вторую группу инъецировали синтетическим препаратом «Сурфагон» в соотношении 20:80, общая доза препарата составила 2,5 мкг/кг. Аналогично, как и в первой группе, проводили предварительную и разрешающую инъекцию самкам, с интервалом в 12 часов. Третью группу инъецировали комбинированно, предварительную инъекцию проводили гипофизом карпа в дозировке 0,6 мг/кг, разрешающую инъекцию проводили синтетическим препаратом «Сурфагон» в количестве 2 мкг/кг.

Оценку качества икры проводили согласно руководству [1].

Полученные результаты подвергали статистической обработке посредством компьютерной программы Microsoft Excel. Взвешивание проб икры проводили на аналитических весах «XS204».

Результаты и их обсуждение. Предварительную инъекцию проводили 6 апреля 2020 года в 22:00, при температуре воды в чиллерах $14{ }^{\circ} \mathrm{C}$. Коэффициент поляризации икры варьировался от 0,13 до 0,18 . Производителей разделили на 3 группы по 20 особей со средней массой особей 3,23 кг, отбирали для опыта преимущественно уже использованных в работе в предыдущих сезонах. Предварительную и разрешающую инъекции самкам, с интервалом в 12 часов, делали согласно разработанной схеме (рисунок).

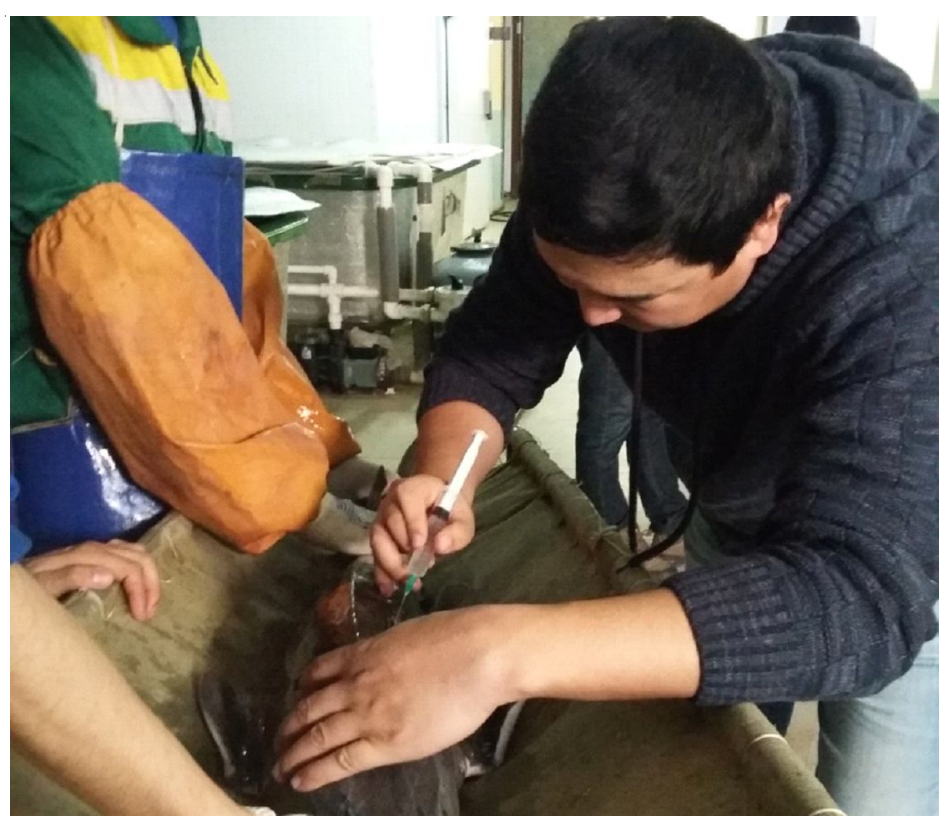

Инъекция производителя синтетическим препаратом для стимулирования ооцитов 


\section{НОВЫЕ БИОТЕХНОЛОГИИ В АГРОПРОМЫШЛЕННОМ КОМПЛЕКСЕ}

Просмотр самок провели после появления первых икринок в бассейне, то есть через 22 часа после разрешающей инъекции (табл. 1).

Первый просмотр длился 3 часа с 08:00 до 11:00 в результате, из 60 особей самок стерляди созрели и отдали икру в намеченное время 22 самки, в том числе из І опытной группы 4 (20 \%) самки, II группы 6 (30 \%) самок и из III группы 16 (80 \%) самок. После первого просмотра через 2 часа провели второй просмотр, который длился 3 часа с 13:00 до 16:00. В этот промежуток времени активно созрели самки І группы 11 (55\%) и II группы 9 (45\%) и оставшаяся часть самок III группы 4 (20\%). Tретей и завершающий просмотр производителей стерляди провели с 16:00 до 18:00. Результаты третьего просмотра показывают, что в І группе икру отдали 3 (15\%) самки, а оставшиеся 2 самки были переведены в общую группу, так как время ожидания созревания у них прошло. Во II группе не отдали икру 5 caмок, их тоже перевели в общую группу.

Заключение. Таким образом, последняя самка отдала икру через 32 часа после разрешающей инъекции. Если брать общую группу, из 60 самок не отдали икру 7 (11,66\%). По завершению эксперимента получили следующее результаты: наилучшие показатели были получены в III группе, при применении комбинированного стимулирования - предварительно инъекцию провели гипофизом, а разрешительную инъекцию сурфагоном. При применении такой схемы самки созрели на 100 \%, масса полученной от каждой самки икры составила в среднем 10,9\% от массы 1 самки. Второй результат по эффективности показала III группа, которую инъекцировали синтетическим препаратом «Нерестин-5». Позитивная реакция на препарат «Нерестин-5» наблюдалась у $90 \%$ самок стерляди, в тоже время наблюдалась задержка по времени созревания. Сравнительно низкую эффективность показала схема с использованием только сурфагона, так во II группе созрели и отдали икру только $75 \%$ самок. Всего от производителей было отобрано 18,35 кг качественной товарной икры.

\section{СПИСОК ЛИТЕРАТУРЫ}

1. Атлас нарушений в гаметогенезе и строении молоди осетровых / Н. В. Акимов [и др.]. - М. : Изд-во ВНИРО, 2004. - 120 с.

2. Бубунец, Э. В. Инновационная модель комбинированного стимулирования овуляции у осетровых рыб и цитометрические особенности продуцируемых ооцитов / Э. В. Бубунец, А. О. Ревякин, А. В. Лабенец // Биомедицина. - 2014. - № 4. C. 65-69.

3. Влияние совокупности различных технологических факторов на эффективность процессов созревания и получения прижизненной икры / Б. Т. Сариев [и др.] // Международный научно-исследовательский журнал. - 2019. - № 10-1 (88). - С. 95-98.

4. Кучко, Т. Ю. Методы получения половых продуктов от производителей рыб : учеб. пособие для студентов экол.-биол. и агротехн. фак. / Т. Ю. Кучко. - Петрозаводск : Изд-во ПетрГУ, 2015. - 63 с.

5. Чебанов, М. С. Руководство по искусственному воспроизводству осетровых рыб № 558 / М. С. Чебанов, Е. В. Галич. - Анкара : ФАО, 2013.$325 \mathrm{c}$.

6. Candrl, J. S. A Minimally Invasive Method for Extraction of Sturgeon Oocytes / J. S. Candrl, D. M. Papoulias, D. E. Tillitt//North American Journal of Aquaculture. - 2010. - Vol. 72, № 2. -P. 184-187.

7. Goncharov, B. F. In Vitro Approach to Studying the Mechanisms of Oocyte Maturation in Sturgeons: A Review of Fundamental and Applied Aspects / B. F. Goncharov // Journal of Applied Ichthyology. - 2002. - Vol. 18. - P. 368-374.

8. Sturgeon Hatchery Practices and Management for Release-Guidelines № 570 / M. Chebanov [et al.]

\section{Результаты получения овулированной икры самок стерляди с помощью различных схем стимулирования}

\begin{tabular}{|c|c|c|c|c|c|c|c|c|c|}
\hline \multirow[t]{2}{*}{ № } & \multirow{2}{*}{$\begin{array}{c}\text { Наименование } \\
\text { группы }\end{array}$} & \multirow[t]{2}{*}{$n$} & \multirow{2}{*}{$\begin{array}{c}\text { Масса рыбы, } \\
\text { кг (среднее) }\end{array}$} & \multirow{2}{*}{$\begin{array}{c}\text { Масса по- } \\
\text { лученной } \\
\text { икры, кг }\end{array}$} & \multirow{2}{*}{$\begin{array}{c}\text { Процентное } \\
\text { отношение } \\
\text { икры к об- } \\
\text { щей массе } \\
\text { рыбы, \% } \\
\end{array}$} & \multicolumn{4}{|c|}{ Количество созревших самок, \% } \\
\hline & & & & & & $\begin{array}{c}\text { с 8:00 до } \\
11: 00 \text { (22- } \\
25 \text { часов) }\end{array}$ & $\begin{array}{l}\text { с 13:00 до } \\
\text { 16:00 (27- } \\
30 \text { часов) }\end{array}$ & $\begin{array}{c}\text { с } 16: 00 \text { до } \\
18: 00 \text { (30- } \\
32 \text { часа) }\end{array}$ & Всего \\
\hline 1 & I группа & 20 & $3,22 \pm 0,125$ & 6,15 & 9,56 & 20 & 55 & 15 & 90 \\
\hline 2 & II группа & 20 & $3,30 \pm 0,103$ & 5,22 & 7,92 & 30 & 45 & - & 75 \\
\hline 3 & III группа & 20 & $3,19 \pm 0,096$ & 6,98 & 10,9 & 80 & 20 & - & 100 \\
\hline
\end{tabular}


// FAO Fisheries and Aquaculture Technical Paper. Ankara, FAO, 2011.-110p.

9. Webb, M. Effects of Steroid Hormones on in Vitro Oocyte Maturation in White Sturgeon / M. Webb, J. van Eenennaam, S. Doroshov // (Acipenser transmontanus). Fish Physiology and Biochemistry. 2000. - vol. 23. - P. 317-325.

\section{REFERENCES}

1. Akimov N.V., Goryunova V.B., Mikodina E.V., et al. Atlas narusheniy $v$ gametogeneze $i$ stroenii molodi osetrovykh [Atlas of Disturbances in Gametogenesis and Structure of Juvenile Sturgeon]. Moscow, Publ. House of All-Russian Research Institute of Fisheries and Oceanography, 2004. 120 p.

2. Bubunec E.V., Revyakin A.O., Labenec A.V. Innovatsionnaya model kombinirovannogo stimulirovaniya ovulyatsii u osetrovykh ryb i tsitometricheskie osobennosti produtsiruemykh ootsitov [An Innovative Model of Combined Stimulation of Ovulation in Sturgeons and the Cytometric Features of the Produced Oocytes]. Biomedicina [Biomedicine], 2014, no. 4, pp. 65-69.

3. Sariev B.T., Tumenov A.N., Bakiyev S.S., et al. Vliyanie sovokupnosti razlichnykh tekhnologicheskikh faktorov na effektivnost protsessov sozrevaniya i polucheniya prizhiznennoy ikry [The Influence of a Combination of Various Technological Factors on the Efficiency of Maturation and Production of Intravital
Caviar]. Mezhdunarodnyy nauchno-issledovatelskiy zhurnal [International Research Journal], 2019, no. 10-1 (88), pp. 95-98.

4. Kuchko T. Yu. Metody polucheniya polovykh produktov ot proizvoditeley ryb: ucheb. posobie dlya studentov ekol.-biol. i agrotekhn. fak. [Methods of Obtaining Sex Products from Fish Producers: a Training Manual for Students of Environmental, Biological and Agrotechnical Faculties]. Petrozavodsk, PetrGU Publ., 2015. 63 p.

5. Chebanov M.S., Galich, E.V. Rukovodstvo po iskusstvennomu vosproizvodstvu osetrovykh ryb № 558 [Guidelines for the Artificial Reproduction of Sturgeons no. 558]. Ankara, FAO, 2013. 325 p.

6. Candrl J.S., Papoulias D.M., Tillitt D.E. A Minimally Invasive Method for Extraction of Sturgeon Oocytes. North American Journal of Aquaculture, 2010, vol. 72, no. 2, pp. 184-187.

7. Goncharov B.F. In Vitro Approach to Studying the Mechanisms of Oocyte Maturation in Sturgeons: A Review of Fundamental and Applied Aspects. Journal of Applied Ichthyology, 2002, vol. 18, pp. 368-374.

8. Chebanov M., Rosenthal H., Gessner J., et al. Sturgeon Hatchery Practices and Management for Release-Guidelines no. 570. FAO Fisheries and Aquaculture Technical Paper. Ankara, FAO, 2011. 110 p.

9. Webb M., van Eenennaam J., Doroshov S. Effects of Steroid Hormones on in Vitro Oocyte Maturation in White Sturgeon (Acipenser Transmontanus). Fish Physiology and Biochemistry, 2000, vol. 23, pp. 317-325.

\section{Information About the Authors}

Arthur N. Tumenov, PhD (Agricultural Sciences), Director, West Kazakhstan Branch "Scientific and Production Center of Fisheries", Zhangir Khana St, 45, 090009 Uralsk, Republic of Kazakhstan, artur_tumen@mail.ru.

Ahmediyar M. Dzhunusov, Master Student, Educational and Scientific Complex of Pilot Industrial Production of Aquaculture, Zhangir Khana St, 51/7a, 090009 Uralsk, Republic of Kazakhstan, ahmed_91kz@mail.ru.

Serik S. Bakiyev, PhD Student (Biological Sciences), Al-Farabi Kazakh National University, Prosp. al-Farabi, 71, 050038 Almaty, Republic of Kazakhstan, serik_2595@mail.ru.

\section{Информация об авторах}

Артур Насибуллаулы Туменов, доктор $\mathrm{PhD}$ (сельскохозяйственные науки), директор, Западно-Казахстанский филиал «Научно-производственный центр рыбного хозяйства», ул. Жангир хана, 45, 090009 г. Уральск, Республика Казахстан, artur_tumen@mail.ru.

Ахмедияр Мирасович Джунусов, магистрант, Учеб̆но-научный комплекс опытно-промышленного производства аквакультуры, ул. Жангир хана, 51/7a, г. Уральск, Республика Казахстан, ahmed_91kz@mail.ru.

Серик Самигуллович Бакиев, $\mathrm{PhD}$ докторант (биологические науки), Казахский национальный университет им. аль-Фараби, просп. аль-Фараби, 71, 050038 г. Алматы, Республика Казахстан, serik_2595@mail.ru. 